\title{
The Diagnosis of Metastatic Axillary Lymph Nodes of Breast Cancer By Diffusion Weighted Imaging: a meta-analysis and systematic review
}

\author{
Wei Fan Sui, Xiang Chen, Zhen Kun Peng, Jing Ye and Jing Tao Wu*
}

\begin{abstract}
Background: The purpose of this meta-analysis was to evaluate the clinical significance of diffusion-weighted imaging in assessing the status of axillary lymph nodes in patients with breast cancer.

Methods: We searched the PubMed, Cochrane, and EMBASE databases, selected studies by inclusion and exclusion criteria, and assessed the quality of selected studies. We explored the source of heterogeneity; calculated sensitivity, specificity, positive and negative likelihood ratios, and pretest probability. A summary receiver operating characteristic curve was performed. Student's $t$ test was used to compare the different mean apparent diffusion coefficient values of different status lymph nodes.

Results: In selected 10 studies, a total of 801 patients and 2305 lymph nodes were included following inclusion criteria. All scores of the quality assessment of the included studies were greater than or equal to 10 points.

The sensitivity was 0.89 (95\% Cl 0.79-0.95), the specificity was 0.83 (95 \% Cl 0.71-0.91), the positive and negative likelihood ratios were 3.86 (95 \% Cl 2.75-5.41) and 0.17 (95\% Cl 0.09-0.32), the pretest probabilities were 53 and $54 \%$, the area under the curve were 0.93 (95\% Cl 0.90-0.95), respectively. The mean apparent diffusion coefficient value of metastatic lymph nodes was significantly lower than that of nonmetastatic axillary lymph nodes.

Conclusions: Diffusion-weighted imaging is a promising tool to discriminate between metastatic and nonmetastatic axillary lymph nodes. Combined with the mean apparent diffusion coefficient value, it can quantitatively diagnose lymph node metastases. Conducting large-scale, high-quality researches can improve the clinical significance of diffusion-weighted imaging to distinguish metastatic and nonmetastatic axillary lymph nodes in patients with breast cancer and provide the evidence to assess the status of axillary lymph nodes.
\end{abstract}

Keywords: Diffusion-weighted imaging, Apparent diffusion coefficient, Breast cancer, Axillary lymph node metastases, Meta-analysis and systematic review

\section{Background}

Evaluating the status of axillary lymph nodes (ALNs) is crucial in staging, deciding the treatment planning, and predicting the long-term survival in breast cancer [1-3]. Biopsy is recognized as the gold standard for assessing ALNs. However, the drawbacks of biopsy are high false negative ratio result from sample errors and its invasiveness [4]. The imaging modalities for assessing the ALNs

\footnotetext{
* Correspondence: wujingtao_2@163.com

Radiology Department, Subei People's Hospital of Jiangsu Province, No.98 of

the Nantong West Road, Yang Zhou, Jiang Su Province, China
}

are rapidly evolving. Ultrasound (US) is applied widely for its convincing and dynamic observation. However, the sensitivity and specificity of ultrasound for lymph node metastasis were unreliable and controversial $[5,6]$. Owing to radiation and relative lower diagnostic accuracy, computer tomography (CT) is limited in clinic [7]. Positron emission tomography (PET) and positron emission tomography/computed tomography (PET/CT) can reflect metabolism of glycolytic activity. Undoubtedly, they have shown the higher diagnostic significance in assessing distant metastases and regional metastatic 
ALNs [8], but their high radiation and expensive fee keep the common people away. Ultrasmall super paramagnetic iron oxide (USPIO) is the same. Its satisfactory performance was extinguished by drawbacks of timeconsuming, underlying risk and forbidden in clinical practice [9].

Magnetic resonance imaging (MRI) is developing with an unimaginable speed; over the past years, it has been used to evaluate ALNs [10]. MRI can detect deep and contralateral lymph nodes. Its sensitivity and specificity for metastatic ALNs were higher than US and CT [11]. Diffusionweighted imaging (DWI) as an advanced technology of
MRI with its superior ability to apparent the diffusion of water molecules freely in tissues [12] has also been useful for diagnosing lymph nodes in the axillary and other sites. Apparent diffusion coefficient (ADC) can quantify the diffusion of water molecules; $\mathrm{ADC}$ value and $\mathrm{ADC}$ ratio were applied to distinguish metastatic from nonmetastatic lymph node widespread [13].

The role of DWI in diagnosing the metastatic ALNs can be found in several published studies; however, the existing results in these studies were enormously varied, and a comprehensive systematic review would be useful to synthesize the current available information.

Primary studies through PubMed, Embase, The Cochrane Libaray $(\mathrm{n}=38)$
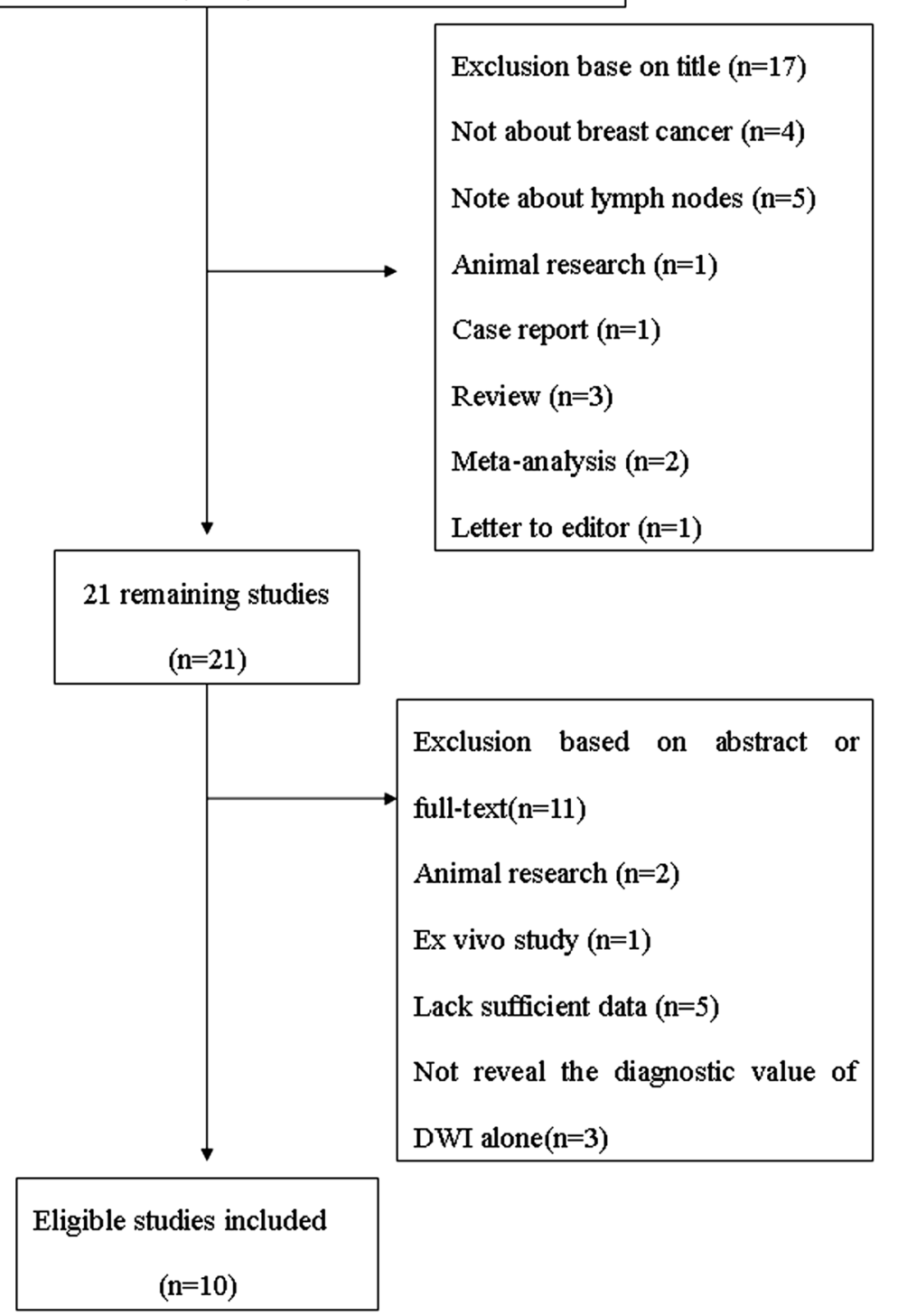

Exclusion based on abstract or
full-text $(n=11)$
Animal research $(n=2)$
Ex vivo study ( $n=1)$
Lack sufficient data ( $n=5)$
Not reveal the diagnostic value of
DWI alone(n=3)

Eligible studies included

$(n=10)$ 
Table 1 Characteristics of inclusion articles

\begin{tabular}{|c|c|c|c|c|c|c|c|c|c|c|c|c|c|c|c|}
\hline Author & Year & Nation & Design & $\begin{array}{l}\text { No. of patients } \\
\text { and nodes }\end{array}$ & $\begin{array}{l}b \text { value } \\
\left(\mathrm{s} / \mathrm{mm}^{2}\right)\end{array}$ & $\begin{array}{l}\text { Field } \\
\text { strength }(T)\end{array}$ & $\begin{array}{l}\text { ADC cutoff } \\
\left(\times 10^{-3} \mathrm{~mm} / \mathrm{s}^{2}\right)\end{array}$ & $\begin{array}{l}\text { Mean ADC of } \\
\text { metastases }\left(\times 10^{-3}\right. \\
\left.\mathrm{mm} / \mathrm{s}^{2}\right)\end{array}$ & $\begin{array}{l}\text { Mean ADC of } \\
\text { benign }\left(\times 10^{-3}\right. \\
\left.\mathrm{mm} / \mathrm{s}^{2}\right)\end{array}$ & Coil & $\begin{array}{l}\text { Reference } \\
\text { standard }\end{array}$ & tp & $\mathrm{fp}$ & fn & tn \\
\hline Nakai & 2011 & Japan & $N G$ & 16,216 & 0,800 & 1.5 & NG & 1.04 & 1.22 & Cardiac surface & Histopathologically & 30 & 4 & 6 & 176 \\
\hline Kamitani & 2012 & Japan & Retro & 108,110 & 0,1000 & 1.5 & 1.05 & 1.08 & 0.92 & Body & Histopathologically & 14 & 11 & 12 & 73 \\
\hline Fornasa & 2013 & Italy & Prosp & 43,43 & 0,800 & 1.5 & 1.09 & 0.88 & 1.4 & $\begin{array}{l}\text { 4-channel } \\
\text { phased array }\end{array}$ & Histopathologically & 18 & 2 & 1 & 22 \\
\hline \multirow[t]{2}{*}{$\mathrm{He}$} & \multirow[t]{2}{*}{2013} & \multirow[t]{2}{*}{ China } & \multirow[t]{2}{*}{$N G$} & \multirow[t]{2}{*}{136,1242} & 500 & \multirow[t]{2}{*}{1.5} & 1.68 & 1.37 & 1.77 & \multirow{2}{*}{$\begin{array}{l}\text { 8-channel phased } \\
\text { array breast }\end{array}$} & \multirow{2}{*}{$\begin{array}{l}\text { Biopsy or surgical } \\
\text { resection }\end{array}$} & 138 & 498 & 4 & 602 \\
\hline & & & & & 800 & & 1.35 & 1.18 & 1.55 & & & 134 & 376 & 8 & 724 \\
\hline Luo & 2013 & China & NG & 36,79 & 0,800 & 1.5 & 0.889 & 0.79 & 1.04 & $\begin{array}{l}\text { 8-channel phased } \\
\text { array breast }\end{array}$ & Histopathologically & 37 & 6 & 8 & 28 \\
\hline Chung & 2013 & $\begin{array}{l}\text { South } \\
\text { Korea }\end{array}$ & $N G$ & 110,110 & 0,1000 & $\begin{array}{l}1.5 \\
3.0\end{array}$ & 0.9 & 0.69 & 1.04 & $\begin{array}{l}\text { 4-channel phased } \\
\text { array breast }\end{array}$ & Histopathologically & 68 & 26 & 22 & 136 \\
\hline Kim & 2014 & $\begin{array}{l}\text { South } \\
\text { Korea }\end{array}$ & Retro & 252,253 & 0,750 & 1.5 & 0.986 & 0.91 & 1.27 & Bilateral breast surface & Biopsy & 69 & 26 & 22 & 136 \\
\hline Schipper & 2014 & Netherlands & Prosp & 50,135 & $\begin{array}{l}0,500 \\
800\end{array}$ & 3.0 & 0.65 & 0.72 & 0.75 & $\begin{array}{l}\text { 32-channel cardiac } \\
\text { sensitivity encoding }\end{array}$ & Histopathologically & 14 & 46 & 8 & 67 \\
\hline Yamaguchi & 2014 & Japan & NG & 16,52 & 0,800 & 1.5 & 0.852 & 0.75 & 1.03 & Breast & Biopsy & 13 & 3 & 3 & 17 \\
\hline Razek & 2015 & Egypt & Prosp & 34,65 & $\begin{array}{l}0,500 \\
1000\end{array}$ & 1.5 & 1.30 & 1.08 & 1.15 & 8-channel breast & Histopathologically & 41 & 0 & 3 & 21 \\
\hline
\end{tabular}

$t p$ true positive, $f p$ false positive, $f n$ false negative, $t n$ true negative, $N G$ not given, Prosp prospective, Retro retrospective 
The aim of this meta-analysis was to assess the clinical value of DWI in detecting ALN metastases in patients with breast cancer.

\section{Methods}

\section{Literature search}

We searched studies about the diffusion-weighted imaging in diagnosing lymph node metastases in the PubMed, EMBASE, and Cochrane library until May 2015 following the key words "diffusion-weighted," "diffusion weighted imaging," "diffusion weighted magnetic resonance imaging," "DWI," "lymph nodes," "axillary," "breast cancer," "breast carcinoma," "ductal cancer," "tubular cancer," and "medullar cancer".

\section{Inclusion and exclusion criteria}

We reviewed studies for the following inclusion criteria: (1) studies were published in English, (2) DWI was performed in detecting ALNs with breast cancer, (3) histopathological results were used as the reference standard, and (4) the true positive (TP), false positive (FP), true negative (TN), and false negative (FN) values can be calculated with sufficient data. We excluded the studies with the following criteria: (1) lack the explanations of DWI-detected ALNs with breast cancer; (2) without histopathological reference standard; (3) insufficient data to get the TP, FP, TN, and FN values; (4) experimental subject was an animal and ex vivo; (5) the type of study was review, case report, letter to editor, and meta-analysis; and (6) unable to get the full text.

\section{Data extraction and quality assessment}

We extracted the following items in each study: author, nation, publication year, sample size, $b$ value, field strength, the cutoff of $A D C$ value, the mean ADC value of the metastatic and nonmetastatic ALNs, study design, and TP, FP, TN, and FN values.

Assessing studies through QUADAS [14], the total score of the included studies must be greater than 10 points or equal to 10 points.

\section{Statistical analysis}

We applied Meta-DiSc version 1.4, Stata 12.0, SPSS 19.0, to analyze data.

In order to assess the clinical significance of DWI, we calculated sensitivity, specificity, positive and negative likelihood ratios (PLR, NLR), and pretest probability and performed a summary receiver operating characteristic (SROC) curve based on the collected studies of TP, FP, $\mathrm{TN}$, and $\mathrm{FN}$ values.

Heterogeneity can affect the accuracy of estimation, and $I^{2}$ index was used to evaluate heterogeneity. There was existing heterogeneity when $P$ value was less than
0.05 and/or $I^{2}$ value was over $50 \%$ [15]. In diagnostic meta-analysis, the threshold effect was considered as an important source of heterogeneity. We used Spearman correlation coefficient in Meta-DiSc version 1.4 to check it. If threshold effect existed in our analysis, we summarized receiver operating characteristic (ROC) curve and calculated the area under the curve (AUC) directly. If no threshold effect existed in our analysis, after calculating the SROC and AUC, we also used meta-regression and subgroup analysis to explore the source of heterogeneity in Meta-DiSc version 1.4. We used Deeks' funnel plot in Stata 12.0 to assess publication bias [16].

Owing to the different mean ADC values in metastatic and nonmetastatic ALNs, we used Student's $t$ test in SPSS 19.0 to compare the different mean ADC values of different status ALNs.

\section{Results}

Selection of studies

We total yielded 38 primary studies after searching the PubMed, EMBASE, and Cochrane library. We excluded 17 studies after reading the title. From the remaining 21 studies, we excluded 11 studies after reading abstract or full text and included 10 studies [13, 17-25]. The detail of selection can be shown in Fig. 1 .

\section{Data extraction and study assessment}

This study included a total of 801 patients and 2305 ALNs of the included 10 studies in this meta-analysis. The detail characteristic data can be seen in Table 1. All the selected studies were conducted with the QUADAS

Table 2 Results of the evaluation of each study according to QUADAS-2

\begin{tabular}{|c|c|c|c|c|c|c|c|c|c|c|c|c|c|c|c|}
\hline & 1 & 2 & 3 & 4 & 5 & 6 & 7 & 8 & 9 & 10 & 11 & 12 & 13 & 14 & Score \\
\hline Nakai & + & + & + & $?$ & + & + & + & + & $?$ & $?$ & $?$ & + & + & + & 10 \\
\hline Kamitani & + & + & + & $?$ & + & + & + & + & - & $?$ & $?$ & + & + & + & 10 \\
\hline Fornasa & + & + & + & + & + & + & + & + & $?$ & $?$ & $?$ & + & + & + & 11 \\
\hline $\mathrm{He}$ & + & + & + & $?$ & + & + & + & + & + & $?$ & $?$ & + & + & + & 11 \\
\hline Luo & + & + & + & $?$ & + & + & + & + & $?$ & $?$ & $?$ & + & + & + & 10 \\
\hline Chuang & + & + & + & $?$ & + & + & + & + & + & + & $?$ & + & + & + & 12 \\
\hline Kim & + & + & + & + & + & + & + & + & $?$ & + & $?$ & + & + & + & 12 \\
\hline Schipper & + & + & + & + & + & + & + & + & + & $?$ & + & + & + & + & 13 \\
\hline Yamaguchi & + & + & + & $?$ & + & + & + & + & + & $?$ & $?$ & + & + & + & 11 \\
\hline Razek & + & + & + & + & + & + & + & + & + & $?$ & $?$ & + & + & + & 12 \\
\hline
\end{tabular}

$+=$ no bias; $-=$ potential bias; $?=$ bias unclear; $1=$ representative spectrum?; 2 = selection criteria clearly described?; 3 = acceptable reference standard?; $4=$ time interval between MRI and pathology?; 5 = partial verification avoided?; 6 = differential verification avoided?; 7 = incorporation avoided?; 8 = description execution of DW-MRI?; 9 = description execution of pathology?; 10 = pathology results blinded?; 11 = DW-MRI results blinded? 12 = clinical data available as in practice?; $13=$ uninterpretable results reported?; 14 = withdraw explained? 
Table 3 Result of meta-regression analysis

\begin{tabular}{llllll}
\hline Variable & Coefficient & $\begin{array}{l}\text { Standard } \\
\text { error }\end{array}$ & $P$ value & $\begin{array}{l}\text { Diagnostic } \\
\text { odds ratio }\end{array}$ & $95 \% \mathrm{Cl}$ \\
\hline Nation & 0.594 & 0.868 & 0.513 & 1.81 & $(0.24 \sim 13.41)$ \\
Field strength & -1.636 & 0.942 & 0.120 & 0.19 & $(0.02 \sim 1.71)$ \\
b value & -0.266 & 1.275 & 0.838 & 0.77 & $(0.04 \sim 13.15)$ \\
Design & 0.165 & 1.141 & 0.888 & 1.18 & $(0.08 \sim 16.38)$ \\
Coil & -0.443 & 1.334 & 0.749 & 0.64 & $(0.03 \sim 15.07)$ \\
\hline
\end{tabular}

Cl confidence interval

test, and their scores were greater than 10 points or equal to 10 points (Table 2).

\section{Heterogeneity test}

We evaluated heterogeneity through $I^{2}$ index in Stata 12.0. We found $P<0.05$ and $I^{2}=8.7 \%$ indicating there was existing heterogeneity in the included studies. We used Spearman correlation coefficient in Meta-DiSc version 1.4 to check threshold effect. We found that the value of Spearman correlation coefficient was -0.064 and $P=0.852$. We can confirm that threshold effect was not the source of heterogeneity in this meta-analysis.

In order to assess the source of heterogeneity further, we applied meta-regression (Table 3 ) and subgroup analysis by adding nation, design, $b$ value, field strength, and coil (Table 4). Meta-regression and subgroup analysis showed that the source of heterogeneity cannot be found in these factors $(P>0.05)$. However, among these studies, the heterogeneity was highly significant $\left(I^{2}>50 \%\right)$. Thus, we should interpret the results carefully.

\section{Diagnostic performance of DWI and publication bias}

The sensitivity, specificity, PLR, NLR, and the AUC of DWI were 0.89 (95\% CI 0.79-0.95), 0.83 (95\% CI 0.71-0.91), 3.86 (95\% CI 2.75-5.41), 0.17 (95\% CI 0.09-0.32), and
0.93 (95 \% CI 0.90-0.95), respectively (Figs. 2, 3, and 4). Figure 5 shows that the post probability positive (PPP) and post probability negative (PPN) were 86 and $13 \%$, respectively, when the pretest probabilities were defined as 53 and $54 \%$.

As presented in Fig. 6, Deeks' funnel plot indicated that we found no significant publication bias among the studies $(P=0.759)$.

\section{The results of $A D C$ values}

We compared the mean ADC values of metastatic and benign ALNs by Student's $t$ test. Figure 7 shows that the mean ADC value of metastatic ALNs was significantly lower than that of benign ALNs $(P<0.000)$.

\section{Discussion}

Diffusion-weighted $M R$ is a noninvasive technique to reflect functional information of tissues and is widely used in diagnosing the malignant lesions. Recently, detecting breast cancer and metastatic ALNs by DWI is a hot spot. We desire to assess the clinical significance of DWI in diagnosing metastatic ALNs in patients with breast cancer through systemic review. We selected 10 studies following the included criteria. We got the high sensitivity, specificity, and AUC as 89,83 , and $93 \%$, respectively. The results demonstrated that DWI was a promising method to differentiate diagnosis metastatic from nonmetastatic ALNs.

We also calculated the PLR and NLR to assess the performance of DWI. PLR and NLR are recognized as the better parameters to test the diagnostic accuracy. They can interpret one diagnostic tool through probability. We can rule in a disease when the PLR $>10$ and rule out a disease when the NLR $<0.1$ [26]. The PLR and NLR were 3.86 (95\% CI 2.75-5.41) and 0.17 (95\% CI

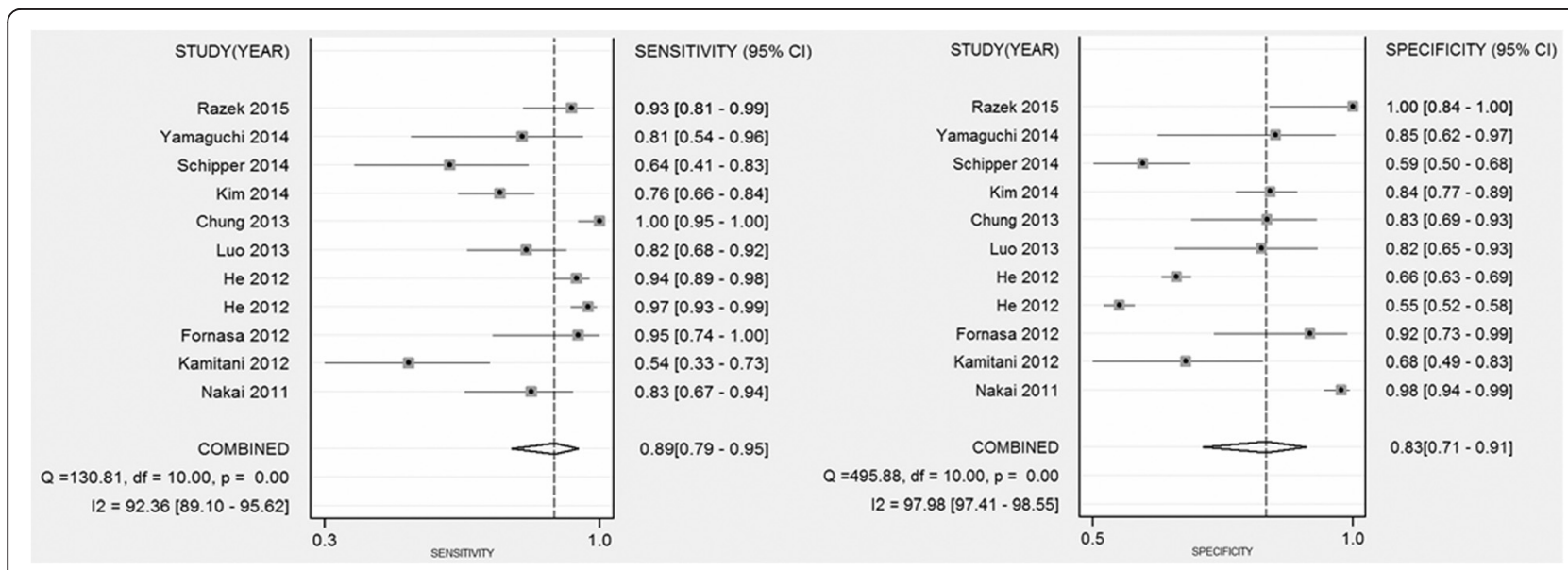

Fig. 2 Forest plots of sensitivity and specificity with corresponding $95 \% \mathrm{Cls}$ of 18 studies. The pooled sensitivity and specificity were 0.89 (95\% Cl 0.79-0.95) and 0.83 (95\% Cl 0.71-0.91), respectively 


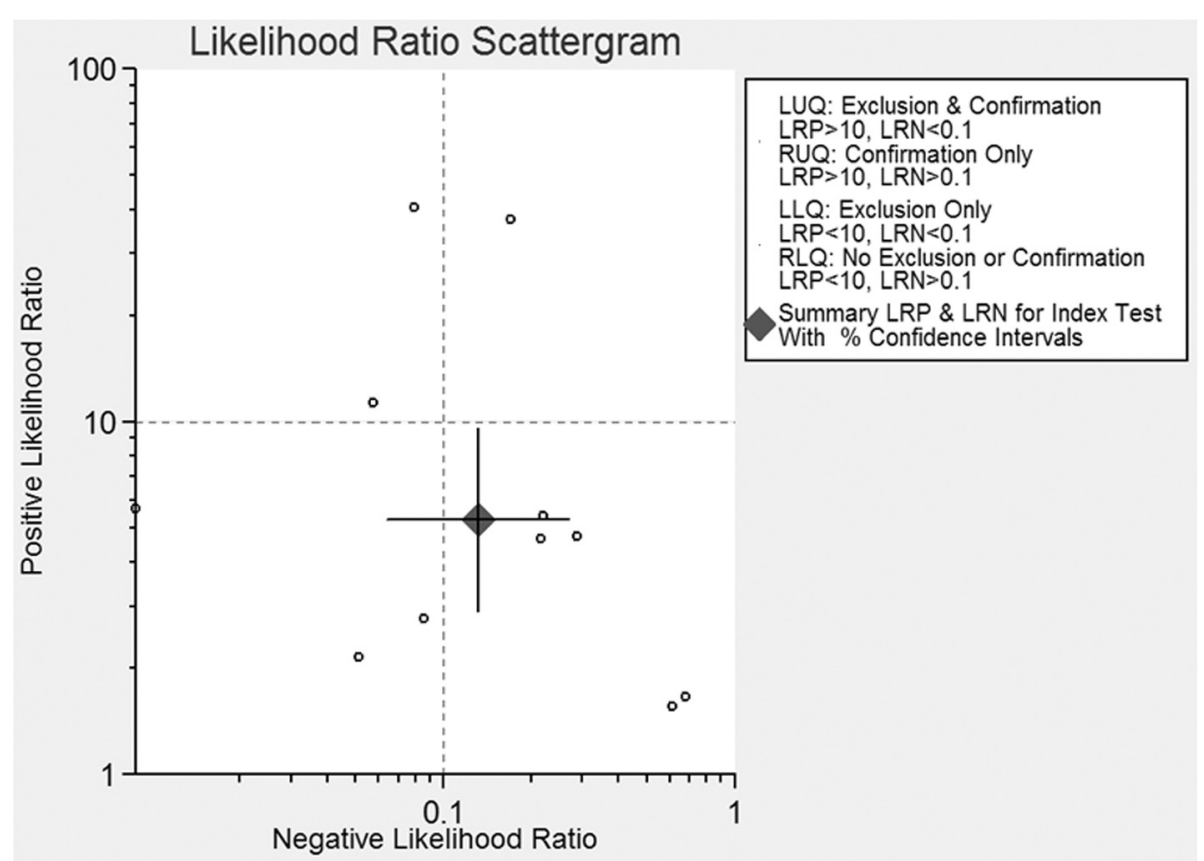

Fig. 3 Scattergram of the PLR and NLR. Pooled estimates for the DWI were as follows: PLR was 3.86 (95\% Cl 2.75-5.41), and NLR was 0.17 (95\% Cl 0.09-0.32). LLQ left lower quadrant, LRN negative likelihood ratio, LRP positive likelihood ratio, LUQ left upper quadrant, RLQ right lower quadrant, RUQ right upper quadrant

0.09-0.32), respectively. The results indicated that DWI could not rule in or rule out metastatic ALNs. Combined with the PLR and NLR, DWI had an inferior capacity to exclude or confirm metastatic ALNs. Fagan's nomogram was also used to estimate the probability of having a disease in patients [27]. In this meta-analysis, the pretest probabilities of a patient with suspected metastatic ALNs were 53 and $54 \%$, and the posttest probability positive and posttest probability negative were 68 and $13 \%$, respectively, after likelihood ratio. The results meant that the pretest probabilities of 53 and $54 \%$ were the cutoff for DWI-diagnosed metastatic

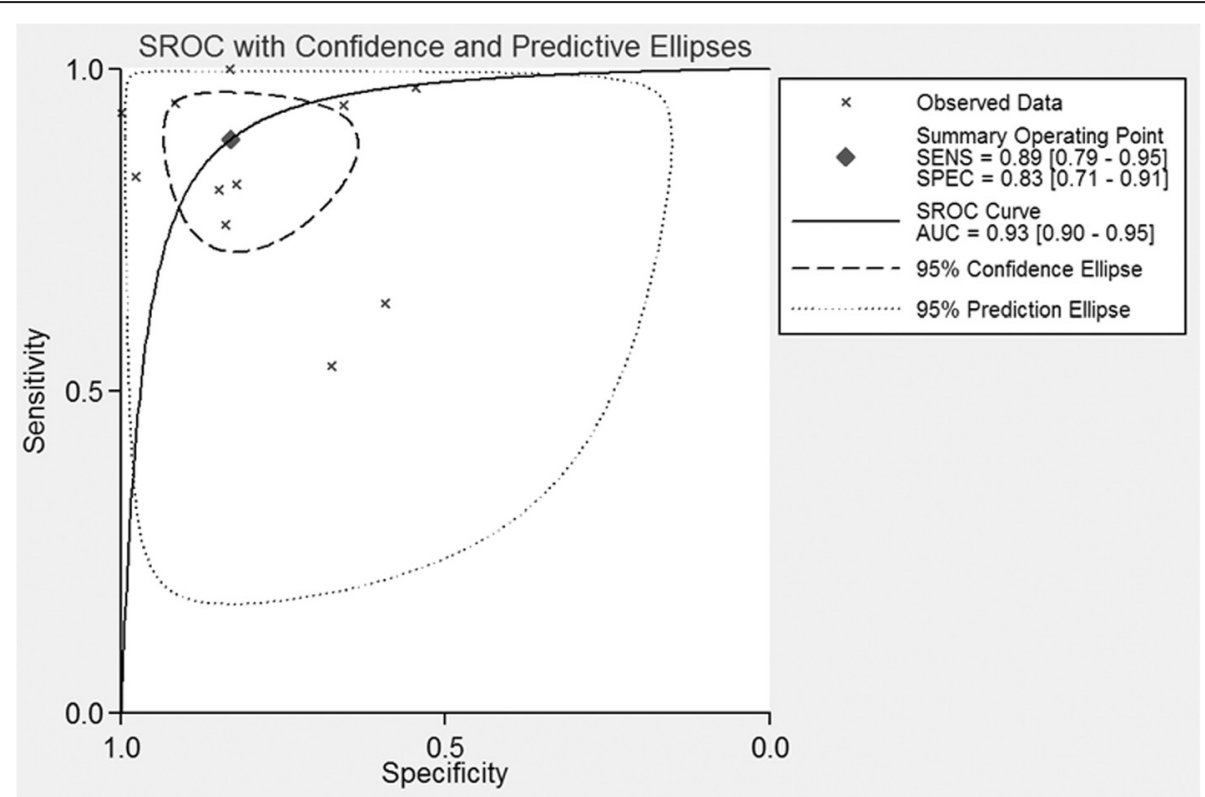

Fig. 4 SROC curve for the diagnostic performance of DWI for all 10 studies combined. The pooled ROC with corresponding $95 \% \mathrm{CI}$ was 0.93 (95\% Cl 0.90-0.95) 


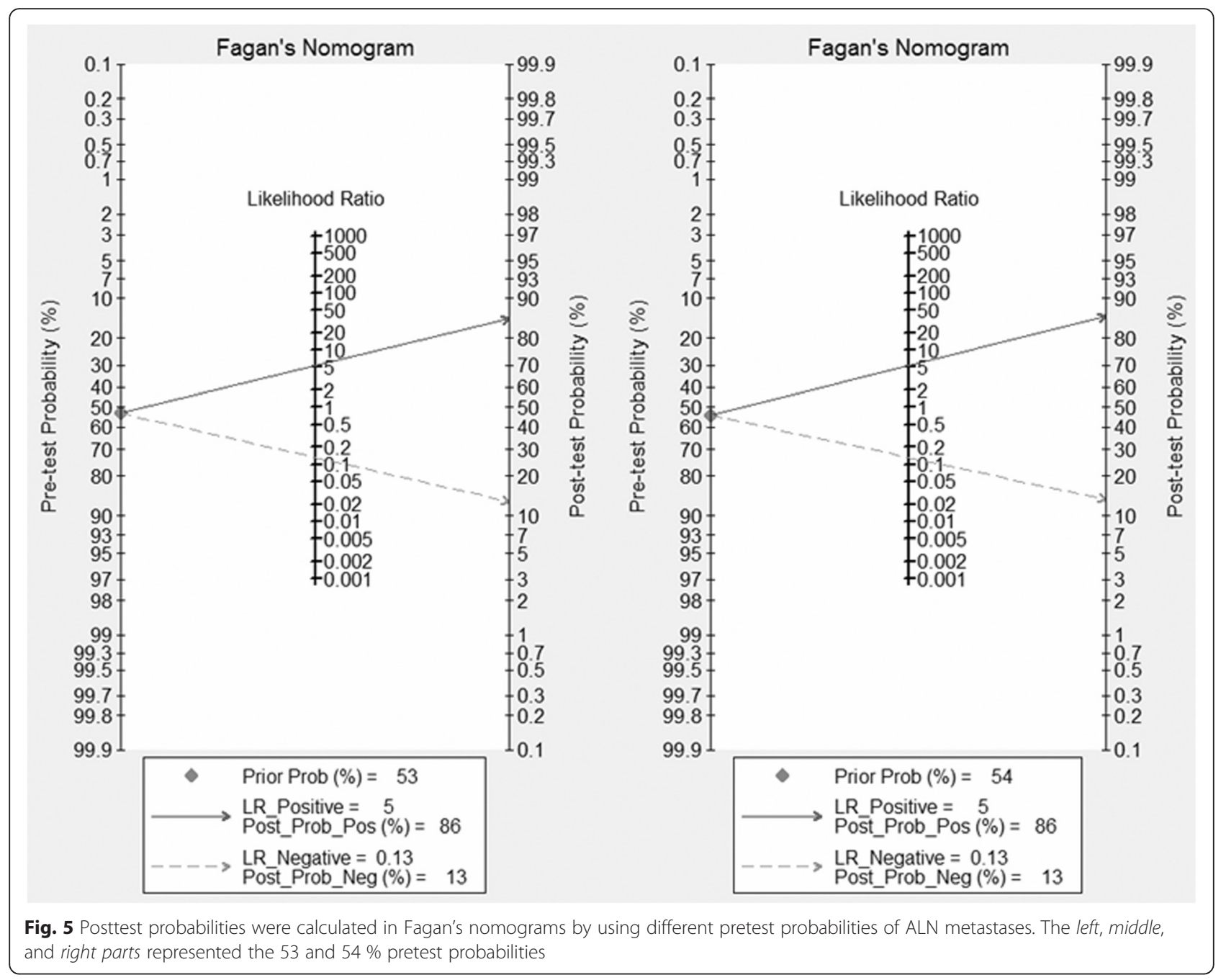

ALNs. We can confirm the metastatic ALNs in patient when the pretest probabilities were higher than 53 and $54 \%$ and excluded the metastatic ALNs in patient when the pretest probabilities were lower than 53 and $54 \%$. Therefore, the performance of DWI in differential diagnosis between metastatic and benign ALNs needs to be lucubrated.

ADC derived from DWI can determine the malignant lesions quantitatively and excluded the effect of T2 shine through [28]. Brownian motion of water molecules in cells can be quantitatively reflected. Wang et al. [29] found that the density of ALNs had significant positive correlation with metastatic lymph nodes and had significant negative correlation with $\mathrm{ADC}$ value. It meant that the diffusion of metastatic ALNs was higher than that of the benign ones and the ADC value of metastatic ALNs was lower than that of the benign ones. In Fig. 7, we found that the mean ADC value of metastatic ALNs was lower than that of the benign ones $(P<0.000)$. However,
Xue et al. [30] and Roy et al. [31] got the opposite results. Actually, owing to the different selected ROI [32], liquefied active necrosis [33], and inflammatory and fibrous connective tissue proliferation [29], we acknowledged that certain overlap existed in metastatic and benign lymph nodes. In order to avoid the overlap, applying ratio of lymph node $\mathrm{ADC}$ value to primary tumor ADC value [34] and relative ADC values [35] may be a better method for detecting lymph node metastasis. Therefore, the clinical significance of different kinds of $\mathrm{ADC}$ values has more perspective. In this meta-analysis, we also found that the cutoff of diagnosing metastatic ALNs were variable and had no statistical significance.

Interestingly, in previous animal research [29], they found that the effect of perfusion can be ignored with $b$ value $\geq 1000$ and the diagnostic performance was better than that of the low $b$ value. Previous study also demonstrated that with higher $b$ value, the more accuracy the ADC had in other tumor [36]. Combined with 


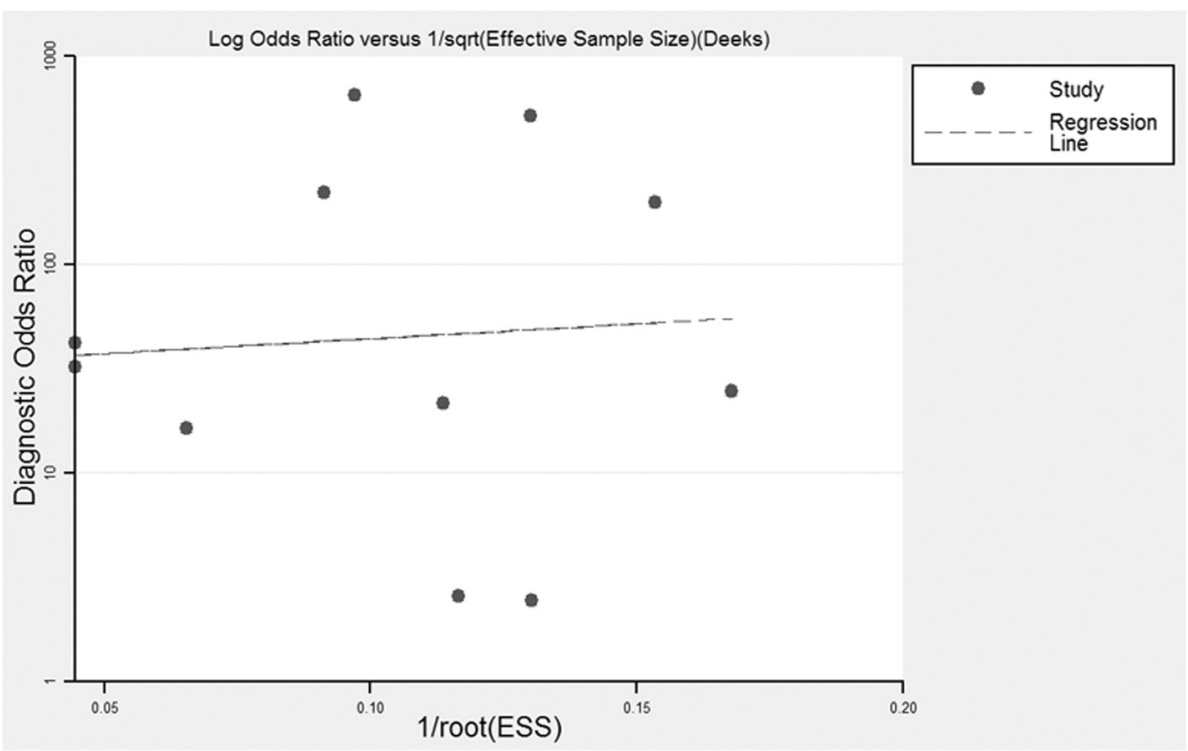

Fig. 6 Deeks' funnel plot indicated no publication bias $(P=0.759)$

professional knowledge, $b$ value may be one of the sources of heterogeneity. In selected studies, the diagnosis performance with high $b$ value was higher than with the lower ones (Table 4). However, with a low $b$ value, owing to the perfusion effect, water diffusion motion cannot be reflected accurately. Moreover, the risk of distortion and susceptibility artifacts existing in DWI with high $b$ value also cannot be ignored [37]. Different $b$ values can affect the measurement of $\mathrm{ADC}$ and cutoff of $\mathrm{ADC}$. It is necessary to get optimal $b$ value for us to assess the statues of ALNs. Unifying the parameters of scan, cutoff of ADC, and optimal $b$ value and improving spatial resolution were the direction of DWI in diagnosing ALN metastases in the future.

We should acknowledge the limitations of this metaanalysis. First, with the limited number of selected studies, we cannot find the source of heterogeneity.

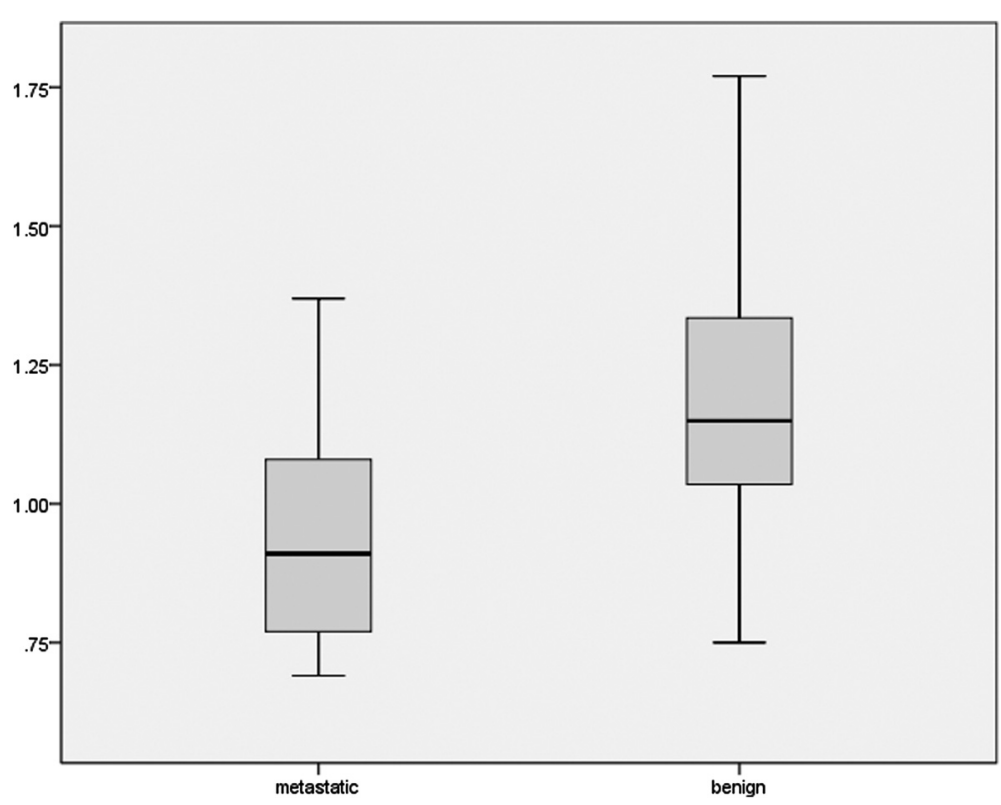

Fig. 7 Box plot showed the comparison of the mean ADC value of metastatic and nonmetastatic ALNs. The mean ADC value of metastatic ALNs was significantly lower than that of the nonmetastatic ones $(P<0.000)$ 
Table 4 The results of subgroup analysis

\begin{tabular}{|c|c|c|c|c|c|c|c|c|}
\hline Variable & Number & Pooled sensitivity & $P^{2}(\%)$ & Pooled specificity & $P^{2}(\%)$ & Positive likelihood ratio & Negative likelihood ratio & Diagnostic odds ratio \\
\hline Retrospective & 3 & $0.729(0.664-0.789)$ & $60.2 \%$ & $0.846(0.807-0.879)$ & 0.0 & $4.628(3.627-5.904)$ & $0.350(0.239-0.514)$ & 14.358 (9.519-21.655) \\
\hline Prospective & 7 & $0.898(0.860-0.929)$ & $78.8 \%$ & $0.625(0.600-0.650)$ & 97.1 & $6.152(2.387-15.857)$ & $0.156(0.072-0.342)$ & $43.259(10.752-174.0)$ \\
\hline Field strength (1.5 T) & 8 & $0.841(0.806-0.872)$ & $85.0 \%$ & $0.678(0.655-0.699)$ & 97.1 & $6.513(2.884-14.711)$ & $0.195(0.12-0.314)$ & $31.716(15.746-63.884)$ \\
\hline Field strength (3.0 T) & 2 & $0.732(0.640-0.811)$ & $18.2 \%$ & $0.738(0.682-0.789)$ & 95.2 & $2.716(0.874-8.438)$ & $0.409(0.197-0.849)$ & $6.644(1.086-40.634)$ \\
\hline$b$ value $<1000\left(\mathrm{~s} / \mathrm{mm}^{2}\right)$ & 8 & $0.867(0.831-0.899)$ & $82.0 \%$ & $0.646(0.6239-0.669)$ & 97.1 & $5.801(2.575-13.066)$ & $0.177(0.09-0.323)$ & 35.007 (12.019-101.96) \\
\hline$b$ value $\geq 1000\left(\mathrm{~s} / \mathrm{mm}^{2}\right)$ & 2 & $0.769(0.696-0.832)$ & $86.8 \%$ & $0.861(0.814-0.901)$ & 71.1 & $4.888(2.753-8.679)$ & $0.264(0.120-0.580)$ & $19.496(5.243-72.498)$ \\
\hline
\end{tabular}


Second, the potential publication bias could not be ignored, although our result showed no significant publication bias. Third, lacking enough high-quality prospective studies may uncover the ability of DWI detecting the metastatic ALNs.

In conclusion, DWI is a promising diagnostic method for differentiation between benign and metastatic ALNs. ADC value can quantitatively analyse ALNs. Larger number of high-quality prospective studies regarding DWI and ADC to detect ALN metastases still need to be performed.

\section{Authors' contributions}

WFS wrote the first draft of the manuscript and contributed to the data collection and analysis. XC and ZKP contributed to the data collection. JY participated in the manuscript drafting and revising. JTW contributed to the study design. All authors read and approved the final manuscript.

\section{Competing interests}

The authors declare that they have no competing interests.

Received: 27 June 2015 Accepted: 14 May 2016

Published online: 02 June 2016

\section{References}

1. Jatoi I, Hilsenbeck SG, Clark GM, Osborne CK. Significance of axillary lymph node metastasis in primary breast cancer. J Clin Oncol. 1999; 17(8):2334-40

2. Silverstein MJ, Skinner KA, Lomis TJ. Predicting axillary nodal positivity in 2282 patients with breast carcinoma. World J Surg. 2001;25(6):767-72.

3. Thompson AM. New standards of care in the management of the axilla. Curr Opin Oncol. 2012;24(6):605-11.

4. Mullen R, Purdie CA, Jordan LB, McLean D, Whelehan P, Vinnicombe S, Brown DC, Evans A. Can additional histopathological examination of ultrasound-guided axillary lymph node core biopsies improve preoperative diagnosis of primary breast cancer nodal metastasis? Clin Radiol. 2013;68(7):704-7.

5. Tsai WC, Lin CK, Wei HK, Yu BL, Hung CF, Cheng SH, Chen CM. Sonographic elastography improves the sensitivity and specificity of axilla sampling in breast cancer: a prospective study. Ultrasound Med Biol. 2013;39(6):941-9.

6. Alvarez S, Anorbe E, Alcorta P, Lopez F, Alonso I, Cortes J. Role of sonography in the diagnosis of axillary lymph node metastases in breast cancer: a systematic review. AJR Am J Roentgenol. 2006; 186(5):1342-8.

7. Nasu Y, Shikishima H, Miyasaka Y, Nakakubo Y, Ichinokawa K, Kaneko T. A study of the assessment of axillary lymph nodes before surgery for breast cancer using multidetector-row computed tomography. Surg Today. 2010;40(11):1023-6.

8. Heusner TA, Kuemmel S, Hahn S, Koeninger A, Otterbach F, Hamami ME, Kimmig KR, Forsting M, Bockisch A, Antoch G, et al. Diagnostic value of full-dose FDG PET/CT for axillary lymph node staging in breast cancer patients. Eur J Nucl Med Mol Imaging. 2009;36(10):1543-50.

9. Harada T, Tanigawa N, Matsuki M, Nohara T, Narabayashi I. Evaluation of lymph node metastases of breast cancer using ultrasmall superparamagnetic iron oxide-enhanced magnetic resonance imaging. Eur J Radiol. 2007;63(3):401-7.

10. Murray AD, Staff RT, Redpath TW, Gilbert FJ, Ah-See AK, Brookes JA, Miller ID, Payne S. Dynamic contrast enhanced MRI of the axilla in women with breast cancer: comparison with pathology of excised nodes. Br J Radiol. 2002;75(891):220-8.

11. Bedi DG, Krishnamurthy R, Krishnamurthy S, Edeiken BS, Le-Petross $H$, Fornage BD, Bassett RJ, Hunt KK. Cortical morphologic features of axillary lymph nodes as a predictor of metastasis in breast cancer: in vitro sonographic study. AJR Am J Roentgenol. 2008;191(3):646-52.
12. Harnan SE, Cooper KL, Meng Y, Ward SE, Fitzgerald P, Papaioannou D, Ingram C, Lorenz E, Wilkinson ID, Wyld L. Magnetic resonance for assessment of axillary lymph node status in early breast cancer: a systematic review and meta-analysis. Eur J Surg Oncol. 2011:37(11):928-36.

13. Luo N, Su D, Jin G, Liu L, Zhu X, Xie D, Liu Y. Apparent diffusion coefficient ratio between axillary lymph node with primary tumor to detect nodal metastasis in breast cancer patients. J Magn Reson Imaging. 2013;38(4):824-8.

14. Whiting P, Rutjes AW, Reitsma JB, Bossuyt PM, Kleijnen J. The development of QUADAS: a tool for the quality assessment of studies of diagnostic accuracy included in systematic reviews. BMC Med Res Methodol. 2003;3:25.

15. Huedo-Medina TB, Sanchez-Meca J, Marin-Martinez F, Botella J. Assessing heterogeneity in meta-analysis: Q statistic or 12 index? Psychol Methods. 2006;11(2):193-206.

16. Deeks JJ. Systematic reviews in health care: systematic reviews of evaluations of diagnostic and screening tests. BMJ. 2001;323(7305):157-62.

17. Nakai G, Matsuki M, Harada T, Tanigawa N, Yamada T, Barentsz J, Narumi Y. Evaluation of axillary lymph nodes by diffusion-weighted MRI using ultrasmall superparamagnetic iron oxide in patients with breast cancer: initial clinical experience. J Magn Reson Imaging. 2011;34(3):557-62.

18. Kamitani T, Hatakenaka M, Yabuuchi H, Matsuo Y, Fujita N, Jinnouchi M, Nagao M, Shirahane K, Tokunaga E, Honda H. Detection of axillary node metastasis using diffusion-weighted MRI in breast cancer. Clin Imaging. 2013;37(1):56-61.

19. Fornasa F, Nesoti MV, Bovo C, Bonavina MG. Diffusion-weighted magnetic resonance imaging in the characterization of axillary lymph nodes in patients with breast cancer. J Magn Reson Imaging. 2012;36(4):858-64.

20. He N, Xie C, Wei W, Pan C, Wang W, Lv N, Wu P. A new, preoperative, MRI-based scoring system for diagnosing malignant axillary lymph nodes in women evaluated for breast cancer. Eur J Radiol. 2012;81(10):2602-12.

21. Chung J, Youk JH, Kim JA, Gweon HM, Kim EK, Ryu YH, Son EJ. Role of diffusion-weighted MRI: predicting axillary lymph node metastases in breast cancer. Acta Radiol. 2014;55(8):909-16.

22. Kim EJ, Kim SH, Kang BJ, Choi BG, Song BJ, Choi JJ. Diagnostic value of breast MRI for predicting metastatic axillary lymph nodes in breast cancer patients: diffusion-weighted MRI and conventional MRI. Magn Reson Imaging 2014:32(10):1230-6.

23. Schipper RJ, Paiman ML, Beets-Tan RG, Nelemans PJ, de Vries B, Heuts EM, van de Vijver KK, Keymeulen KB, Brans B, Smidt ML et al. Diagnostic performance of dedicated axillary T2- and diffusion-weighted MR imaging for nodal staging in breast cancer. Radiology. 2015;275(2):345-55.

24. Yamaguchi K, Schacht D, Nakazono T, Irie H, Abe H. Diffusion weighted images of metastatic as compared with nonmetastatic axillary lymph nodes in patients with newly diagnosed breast cancer[J]. Journal of Magnetic Resonance Imaging. 2015;42(3):771-778.

25. Razek AA, Lattif MA, Denewer A, Farouk O, Nada N. Assessment of axillary lymph nodes in patients with breast cancer with diffusion-weighted MR imaging in combination with routine and dynamic contrast MR imaging[]]. Breast Cancer, 2015: 1-8.

26. Jaeschke R, Guyatt GH, Sackett DL. Users' guides to the medical literature. III. How to use an article about a diagnostic test. B. What are the results and will they help me in caring for my patients? The Evidence-Based Medicine Working Group. JAMA. 1994;271(9):703-7.

27. Fagan TJ. Letter: nomogram for Bayes theorem. N Engl J Med. 1975; 293(5):257.

28. Kim JK, Jang YJ, Cho G. Multidisciplinary functional MR imaging for prostate cancer. Korean J Radiol. 2009;10(6):535-51.

29. Junping W, Tongguo S, Yunting Z, Chunshui Y, Renju B. Discrimination of axillary metastatic from nonmetastatic lymph nodes with PROPELLER diffusion-weighted MR imaging in a metastatic breast cancer model and its correlation with cellularity. J Magn Reson Imaging. 2012;36(3):624-31.

30. Xue HD, Li S, Sun F, Sun HY, Jin ZY, Yang JX, Yu M. Clinical application of body diffusion weighted MR imaging in the diagnosis and preoperative N staging of cervical cancer. Chin Med Sci J. 2008;23(3):133-7.

31. Roy C, Bierry G, Matau A, Bazille G, Pasquali R. Value of diffusion-weighted imaging to detect small malignant pelvic lymph nodes at $3 T$. Eur Radiol. 2010;20(8):1803-11.

32. Cho EY, Kim SH, Yoon JH, Lee Y, Lim YJ, Kim SJ, Baek HJ, Eun CK. Apparent diffusion coefficient for discriminating metastatic from non-metastatic lymph nodes in primary rectal cancer. Eur J Radiol. 2013;82(11):e662-8.

33. Sumi M, Van Cauteren M, Nakamura T. MR microimaging of benign and malignant nodes in the neck. AJR Am J Roentgenol. 2006;186(3):749-57. 
34. Yasui $\mathrm{O}$, Sato M, Kamada A. Diffusion-weighted imaging in the detection of lymph node metastasis in colorectal cancer. Tohoku J Exp Med. 2009;218(3):177-83.

35. Lin G, Ho KC, Wang JJ, Ng KK, Wai YY, Chen YT, Chang CJ, Ng SH, Lai CH, Yen

TC. Detection of lymph node metastasis in cervical and uterine cancers by diffusion-weighted magnetic resonance imaging at 3T. J Magn Reson Imaging. 2008;28(1):128-35.

36. Abdel RA, Soliman NY, Elkhamary S, Alsharaway MK, Tawfik A. Role of diffusion-weighted MR imaging in cervical lymphadenopathy. Eur Radiol. 2006;16(7):1468-77.

37. Bastin ME. Correction of eddy current-induced artefacts in diffusion tensor imaging using iterative cross-correlation. Magn Reson Imaging. 1999:17:1011-24.

Submit your next manuscript to BioMed Central and we will help you at every step:

- We accept pre-submission inquiries

- Our selector tool helps you to find the most relevant journal

- We provide round the clock customer support

- Convenient online submission

- Thorough peer review

- Inclusion in PubMed and all major indexing services

- Maximum visibility for your research

Submit your manuscript at www.biomedcentral.com/submit 